Document downloaded from:

http://hdl.handle.net/10251/103285

This paper must be cited as:

Serrano, J.; Bermúdez, V.; Piqueras, P.; Angiolini, E. (2017). On the impact of DPF downsizing and cellular geometry on filtration efficiency in pre- and post-turbine placement. Journal of Aerosol Science. 113:20-35. doi:10.1016/j.jaerosci.2017.07.014

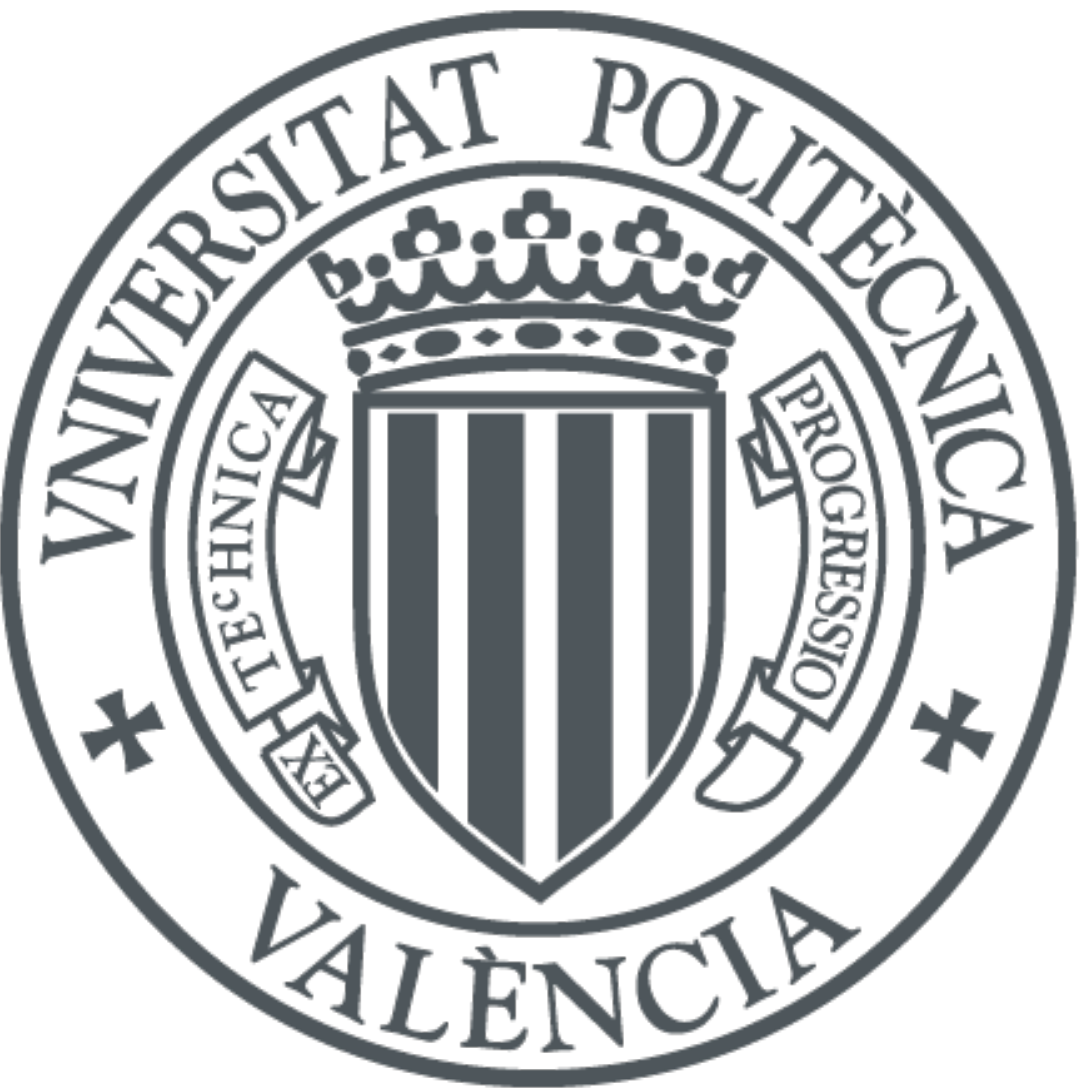

The final publication is available at

https://doi.org/10.1016/j.jaerosci.2017.07.014

Copyright Elsevier

Additional Information 


\title{
On the impact of DPF downsizing and cellular geometry on filtration efficiency in pre- and post-turbine placement
}

\author{
José Ramón Serrano, Vicente Bermúdez, Pedro Piqueras*, Emanuele Angiolini \\ Universitat Politècnica de València, CMT-Motores Térmicos, Camino de Vera s/n, 46022 Valencia, Spain.
}

\begin{abstract}
The use of aftertreatment systems in reciprocating internal combustion engines is currently mandatory in order to comply worldwide with emission standards. Among these systems, the wall-flow diesel particulate filter (DPF) is in charge of the particulate matter removal. The DPF is conventionally placed downstream of the turbine. However, its placement upstream of the turbine is growing in interest because of the benefits in specific fuel consumption, passive regeneration and aptitude to downsizing.

In the current work an in-house 1D wall-flow DPF model is applied to evaluate the effect of the DPF downsizing on filtration efficiency. Both pre- and post-turbine placement are considered in presence of clean and soot loaded substrates. Volume reduction is approached considering diameter and length variation. In parallel, the cell density is also varied modifying the meso-geometry, i.e. cell size and porous wall thickness, imposing constant thermal integrity factor. The sensitivity to this last parameter is also analysed being its influence of second order in comparison to volume and cellular geometry effects. The lower Peclet number in the pre-turbine placement leads to higher filtration efficiency than post-turbine location comparing at the same DPF volume. Diameter based volume reduction provides slightly better results in filtration efficiency because of the way the filtration velocity field is varied. This general behaviour involves additional advantages to the potential for volume reduction of pre-turbine DPFs. Thus, different strategies with boundaries defined by volume reduction at constant filtration area or at constant specific filtration area can be approached looking for the best balance between fuel economy reduction and filtration efficiency increase with pre-turbine DPF placement.
\end{abstract}

Keywords: Diesel engine, particulate matter, DPF sizing, cell size, filtration efficiency, pre-turbine aftertreatment

\section{Introduction}

Wall-flow diesel particulate filters (DPF) are widely used as a part of the aftertreatment systems in Diesel engines because of their high filtration capability combined with reduced pressure drop (Guan (2006)). These devices

\footnotetext{
* Pedro Piqueras. CMT-Motores Térmicos, Universitat Politècnica de València, Camino de Vera s/n, 46022 Valencia, Spain. Phone: +34 963877650 Fax: +34963877659 e-mail: pedpicab@ mot.upv.es
} 
guarantee the fulfilment of the most restrictive emission standards as Euro 6 in Europe (Official Journal of the European Union (2007)), which sets limits to particulate matter in mass and number. Limits apply to Diesel and new generation of direct injection gasoline engines (Mamakos et al. (2013b)). This is extending the use of wall-flow particulate filters from Diesel to gasoline engines as the only system reaching targets in particulate number emission (Mamakos et al. (2013a)).

Besides increase of fuel consumption because of the increased engine back-pressure (Lújan et al. (2015a)), the installation of the particulate filter has an important impact on the final cost of the engine. More than $50 \%$ of control emission technologies cost, which is close to $30 \%$ of the engine cost, is estimated to come from aftertreatment systems in passenger car engines (Posada et al. (2013)). The most important contribution comes from the selective catalytic reduction system (SCR) (50\%), followed by the DPF (40\%) and the diesel oxidation catalyst (DOC) (10\%). These figures, both for total aftertreatment contribution and for DPF cost, are even conservative if compared with data in EPA \& NHTSA (2010) and NAS (2011) reports.

Early literature refers a DPF volume almost equal to the engine displacement and an aspect ratio, i.e. L/D, on the order of 1 (Konstandopoulos \& Johnson (1989)). More recent data from EPA (2000) describe DPF volume for heavyduty applications ranging between 1.5 and 2.5 times the engine displacement for cordierite filters. In case of light and medium-duty vehicles, filter volumes for $\mathrm{SiC}$ monoliths reach up to 2 times the engine displacement (Blanchard et al. (2002); Kai et al. (2009)). Both the applications present a monolith aspect ratio around 1.5 in most cases.

DPF technology is in a state of optimization and cost reduction (Johnson (2009)). Such a cost reduction has to keep high filter performance, which is directly related with the monolith volume decrease (Posada et al. (2013)). It is usually considered that pressure drop diminishes as the volume increases because of the filtration velocity reduction with the increasing filtration area. Nevertheless both pressure drop and ash accumulation are also related to the particular definition of the cellular geometry, which is key to set the DPF performance. The effect on pressure drop was discussed by Konstandopoulos et al., who computed the optimum cell size to minimise the DPF pressure drop in clean (Konstandopoulos et al. (1999)) and soot loaded monoliths (Konstandopoulos \& Kladopoulou (2004)) keeping constant the porous wall thickness. However, thermal (Lee et al. (2009)) and mechanical (Depcik \& Hausmann (2013)) performance must be also taken into account. Thus, Serrano et al. (2014a) obtained an expression to determine the optimum cellular geometry, i.e. cell size and porous wall thickness, as a function of the thermal integrity factor (TIF). The effective length and, specially, the permeability have also impact on the optimized cellular geometry because of the effect on the velocity field (Liu et al. (2009)): the longer the effective length and the lower the permeability the smaller the optimum cell density. Therefore, the aspect ratio of the monolith and the micro-scale geometry, i.e. porosity and mean pore diameter defining the permeability (Payri et al. (2011)), also play an important role.

The volume role on cost requires the location of the aftertreatment, and in particular of the DPF, in the exhaust line to be considered as an additional variable. In post-turbine DPF placement, previous studies (Serrano et al. (2014a)) revealed that the pressure drop, and hence fuel consumption, is very sensitive to volume reduction. In addition, the reduction of volume based on diameter variation is much more damaging than the based on monolith length reduction 
mainly because of the increasing inertial contribution to pressure drop (Serrano et al. (2014b)). The penalty in pressure drop might be counteracted increasing the cell density, i.e. the filtration area. However, the lower capability for ash accumulation and the risk of inlet channels plugging because of the high expected soot loading would become critical constraints. Other approaches to reduce the optimum cell density might be driven to increase the filtration area increasing TIF. It also improves the strain tolerance but damages the mechanical integrity.

In contrast to post-turbine DPF placement, pre-turbine DPF placement has demonstrated better aptitude to DPF downsizing concerning the influence on engine specific fuel consumption (Serrano et al. (2014a)). On one hand, pre-turbine DPF placement confirmed lower pressure drop independently of the volume and the strategy to reduce it, i.e. diameter or length-based (Serrano et al. (2014b)). On the other hand, the fuel consumption is scarcely sensitive to volume and soot loading changes because of the pressure drop location with respect to the turbine. These results have been also observed in experimental studies covering particular applications in passenger car engines under steady (Lújan et al. (2015a)) and transient (Lújan et al. (2015b)) operating conditions, in heavy-duty engines (Bermúdez et al. (2013)) and in large bore engines (Brüstle et al. (2011)). The DPF volume might be decreased more than $40 \%$ in pre-turbine placement (Serrano et al. (2014a)). Such a reduction would provide better engine and VGT response under cold wall transient operation but the use of a mechanical supercharger would still be necessary to attain satisfactory driving performance.

The DPF volume reduction in pre-turbine placement has not effect on fuel economy under clean DPF conditions. Under DPF soot loading conditions the fuel consumption is even lower than that in post-turbine placement with clean DPF. As in post-turbine DPF placement, if the cell geometry is modified to keep constant the filtration area the benefits in pressure drop reduction lead to almost constant fuel consumption independently of the monolith volume. This solution has as limit channel plugging issues due to high cell density. Nevertheless, soot loading in pre-turbine DPF configuration is expected to be low because of the high DPF operating temperature. Therefore, a balance solution between constant specific filtration area and constant filtration area sizing strategies as volume reduces exists. It should provide safe DPF operation and low pressure drop with minimum fuel consumption penalty. In addition, the lack of sensitivity of pre-turbine DPF configuration to soot loading is also applicable to ash loading, which has also influence on pressure drop and filtration efficiency (Jiang et al. (2016)). It results in the increase of the critical ash mass able to be accumulated per unit of volume. Consequently, volume reduction and a suitable design of the cellular geometry may provide improved fluid-dynamic response with good thermal, mechanical and ash loading performance. Therefore, a margin for important DPF volume reduction can be still attainable preserving engine and DPF performance.

As the main function of the DPF is to collect soot to abate particulate matter emissions, the DPF downsizing must be also analysed concerning the absence of any negative impact on the filtration capability. In the present study an inhouse 1D wall-flow DPF model is applied to evaluate the effect of the DPF downsizing and cellular geometry variation on filtration efficiency. Such an influence is discussed regarding both pre- and post-turbine placement as well as in clean and soot loaded substrates. Volume reduction is performed considering the different macro-scale parameters, i.e. diameter or length variation, to analyse their effects separately. Concerning the meso-geometry, cell size and 
porous wall thickness are varied together to keep constant TIF. The analysis is finally focused on the understanding of volume reduction effect on filtration efficiency for different TIF values based on constant filtration area or constant cell density criteria. Thus, a complete characterisation of how the macro-and meso-geometry of the filter influence the soot filtration efficiency is performed.

\section{Methodology}

\subsection{Computational tool}

The open-source gas dynamics software OpenWAM ${ }^{\mathrm{TM}}($ OpenWAM website (2016); Galindo et al. (2009)) for internal combustion engines and components modelling has been used in this work to perform the computational study. As a first step, the engine model was tuned up from experimental data obtained in an engine test bench. The main characteristics of the passenger car engine are reported in Table 1. Reference tests were performed under steadystate operating conditions both for the post- and pre-turbine aftertreatment configuration of the exhaust line. In the original exhaust line layout, i.e. post-turbine aftertreatment configuration, the aftertreatment system was composed of a close-coupled DOC next to the VGT, an underfloor DOC and a wall-flow DPF. In the case of the pre-turbine aftertreatment configuration the close-coupled DOC was removed keeping the same DOC and DPF devices. Table 2 summarises the characteristics of the DPF, which is used as baseline for sizing analysis in forward sections.

A comparison between experimental data and modelled results of the most relevant engine parameters is reported in Figure 1 for post- and pre-turbine aftertreatment configurations. Engine operating points cover steady-state conditions at medium-high load from $1500 \mathrm{rpm}$ to $3000 \mathrm{rpm}$ in engine speed. The engine load varies for every engine speed being $90 \%$ at $1500 \mathrm{rpm} ; 80 \%$ at $2000 \mathrm{rpm}$ and $2500 \mathrm{rpm}$, and $70 \%$ at $3000 \mathrm{rpm}$. The model shows good accuracy and capability to reproduce correctly the main magnitudes describing the engine performance regardless the exhaust line configuration.

With respect to the 1D wall-flow DPF, the model implemented in OpenWAM ${ }^{\mathrm{TM}}$ is described in detail in different works related to numerical solution (Torregrosa et al. (2011); Desantes et al. (2012)) as well as heat transfer (Galindo et al. (2012)), pressure drop (Serrano et al. (2013)) and filtration processes (Serrano et al. (2016)). The model is based on the computation of the porous wall behaviour as a packed bed of spherical particles. Soot emission is characterised by the mode of the particle size distribution (PSD), which governs pressure drop and filtration efficiency.

A detailed description and validation of the filtration efficiency sub-model can be found in the work of Serrano et al. (2016). The main features of the model are described next as a basis for the analysis of the obtained results.

Three different particle collection mechanisms are considered: Brownian diffusion, interception and inertial. Brownian diffusion is the most important mechanism contributing to the overall DPF filtration efficiency. The contribution of this mechanism is governed by the ratio between diffusion and advection transport, which is evaluated by means of the Peclet number across the loaded region of the porous wall. For every particle diameter $i$ the Peclet number is calculated as 


$$
P e_{w_{i}}=\frac{u_{i, w} d_{c, w}}{D_{\text {part }_{i}}}
$$

where the interstitial velocity is defined as the ratio between the filtration velocity and the porous wall porosity:

$$
u_{i, w}=\frac{u_{w}}{\varepsilon_{w}}
$$

Known the Peclet number, the Brownian efficiency of an isolated collector unit is defined as (Lee \& Gieseke (1979)):

$$
\eta_{D_{i}}=3.5\left(\frac{\varepsilon_{w}}{K}\right)^{\frac{1}{3}} P e_{w_{i}}^{-\frac{2}{3}}
$$

The analysis of equations 1 and 3 reveals the importance of the flow conditions on the particles collection by diffusion mechanism. It is due to the direct influence of filtration velocity and temperature, which mainly sets the particle diffusion coefficient $\left(D_{\text {part }}\right)$ :

$$
D_{\text {part }_{i}}=\frac{T k_{B} S C F_{w}}{3 \pi \mu d_{\text {part }_{i}}}
$$

Micro-geometry of the porous wall is also key on the filtration efficiency due to Brownian diffusion by means of the collector unit diameter and the porosity, which in turn sets the Kuwabara's hydrodynamic factor $K$ (Bollerhoff et al. (2012)) and the interstitial velocity. Nevertheless, the influence of these parameters is out of the scope of this study, which focuses on DPF macro-and meso-geometry as well as placement effect on fluid-dynamic properties.

The second collector mechanism in importance is the interception one. It is related to the particle to collector unit diameter ratio, according to equation 5. Indeed, this collection mechanism does not depend on the flow field but has a strong dependence on the porous wall microstructure. Thus, it is to gain weight on the overall filtration efficiency as the porous wall gets loaded.

$$
\begin{gathered}
\eta_{R_{i}}=1.5 \frac{N_{R_{i}}^{2}}{1+N_{R_{i}}^{\frac{3-2 \varepsilon_{w} w}{3{ }_{w}}}} \frac{\varepsilon_{w}}{K} \\
N_{R_{i}}=\frac{d_{p a r t_{i}}}{d_{c, w}}
\end{gathered}
$$

The last collection mechanism considered by the model is the inertial deposition. It is related to the inability of a particle of changing its trajectory when the flow stream gets near to the collector unit. The inertial collection efficiency is calculated from the Stokes number (Rosner \& Tandon (1995)).

$$
\begin{gathered}
\eta_{I_{i}}=\frac{S t_{i}^{2}}{\left(S t_{i}+0.25\right)^{2}} \\
S t_{i}=\frac{S C F_{w} \rho_{s, w} u_{i, w} d_{p a r t_{i}}^{2}}{9 \mu d_{c, w}} \\
5
\end{gathered}
$$


Although this contribution is dependent on the flow field and the porous wall microstructure, it is completely negligible within the characteristic PSD (Kittelson (1998); Burtscher (2005)) in internal combustion engines (Gong \& Rutland (2015)).

Known the filtration efficiency of an isolated collector unit caused by every deposition mechanism it is possible to compute the combined efficiency applying the independence rule (Ferrel (1971)):

$$
\eta_{D R I_{i}}=1-\left(1-\eta_{D_{i}}\right)\left(1-\eta_{R_{i}}\right)\left(1-\eta_{I i}\right)
$$

Finally, the overall filtration efficiency, i.e. that related to the packed bed of spherical particles, of every control volume in which the DPF channels are axially discretised is obtained considering the mass balance of particles through the control volume (Logan et al. (1995)), which leads to

$$
E_{f, w_{i}}=1-e^{-\frac{3 \eta_{m e c}\left(1-\varepsilon_{w}\right) w_{w} f_{w} S_{c}}{2 \varepsilon_{w} d, w}}
$$

where the subscript $\eta_{\text {mec }}$ refers to the filtration efficiency of an isolated collector unit. In this work the overall filtration efficiency due to Brownian diffusion $\left(\eta_{D_{i}}\right)$ and interception $\left(\eta_{R_{i}}\right)$ mechanisms are analysed separately and combined $\left(\eta_{D R I_{i}}\right)$ in order to get better understanding on the nature of the filtration efficiency changes.

\subsection{Parametric study}

The selected operating point for the analysis of the DPF filtration efficiency is defined by an engine load of $80 \%$ and $2500 \mathrm{rpm}$ in engine speed. It is the same engine operating point as in the work of Serrano et al. (2014a), which focused in DPF pressure drop and fuel economy, so that conclusions can be shared between both works.

The parametric study is defined by variations in meso-and macro-geometric parameters. Concerning mesogeometry, cell density $(\sigma)$ has been swept limiting the maximum value to $500 \mathrm{cpsi}$ in order to avoid inlet channels plugging issues (Merkel et al. (2001)). The cell density has been defined imposing constant cell size $(\alpha)$ to porous wall thickness $\left(w_{w}\right)$ ratio. According to equations 11 and 12, this condition means that TIF can be kept constant. The parametric study has covered the analysis of the baseline TIF and its reduction and increase to identify its effect on filtration efficiency.

$$
\begin{aligned}
& \sigma=\frac{1}{\left(\alpha+w_{w}\right)^{2}} \\
& T I F=1+\frac{\alpha}{w_{w}}
\end{aligned}
$$

Macro-geometry variation has included two approaches for monolith volume swept based on diameter and length. In both cases maximum volume has been set by baseline geometry. The criteria to define the minimum volume is that with maximum cell density (500 cpsi) the baseline filtration area must be reached. Thus, minimum volume is 1.571 . 
All these geometric variations have been calculated in clean and soot loading conditions for post- and pre-turbine aftertreatment configuration. The soot loading has been fixed to a low value $(0.2 \mathrm{~g})$ in order to avoid the saturation of the porous wall in all monolith volumes, thus ensuring that filtration efficiency has not reached maximum value close to $100 \%$. This way the comparison between computations provides insights of the filtration efficiency dynamics during loading processes. The soot penetration inside the porous wall was set to the $2 \%$ of the wall thickness, which represents a proper order of magnitude for all cases despite of the Peclet number variation between geometries (Serrano et al. (2016)). Such a small value is in agreement also with the experimental evidences found several authors Fino et al. (2009); Hanamura et al. (2009), in which it was observed a penetration depth only limited to the surface pores opened on the wall surface.

\subsection{Pulsating flow influence on filtration efficiency}

The placement of the DPF upstream of the turbine results in inlet DPF unsteady flow, i.e. pulsating, instead of quasi-steady flow characteristic of region downstream of the turbine. Figure 2 shows a comparison between the instantaneous pressure, filtration velocity and efficiency in the axial position $L_{e} / 2$ in pre- and post-turbine configuration. Figure 2(a), which plots the instantaneous inlet pressure, clearly states the different nature of the flow across the DPF as a function of its placement. The Peclet number is the main parameter controlling the change in filtration efficiency in a particular DPF because of the Brownian diffusion. It is dependent on the filtration velocity, which is represented in Figure 2(b), and gas temperature. The relevant changes in instantaneous filtration efficiency in pre-turbine placement, which is depicted in Figure 2(c), are governed by its inverse relation with filtration velocity, which is much variable in percentage than instantaneous gas temperature, leading to variations over $50 \%$ during in-cycle assessment. This result contrasts with the profile of instantaneous filtration efficiency in post-turbine DPF configuration. Although the influence of filtration velocity is still noticed, the small variation of this variable along the cycle leads to almost constant filtration efficiency.

Such a filtration efficiency dependence on instantaneous flow field leads to the need to properly define its averaged value during the engine cycle, specially in pre-turbine placement. A direct averaging of the instantaneous filtration efficiency is wrong. It involves the assignment of the same weight to the highest in-cycle filtration efficiency, which corresponds to the smallest mass flow (i.e. filtration velocity), that to the lowest filtration efficiency. However, this last value is more relevant on the amount of soot that is collected because it is related to the maximum mass flow across the porous medium. Therefore, it is proposed to weigh the filtration efficiency with the mass flow at every time-step in order to quantify the in-cycle averaged filtration efficiency in every control volume in which the monolith channels are meshed in the axial direction.

$$
\bar{E}_{f_{C V_{j}}}=\frac{\sum_{t_{c}}^{t_{c}} E_{f_{C V_{j}}} \dot{m}_{w C V_{j}} \Delta t}{\sum \dot{m}_{w C V_{j}} \Delta t}
$$


The assessment of the in-cycle averaged filtration efficiency according to equation 13 in the axial position $L_{e} / 2$ in pre- and post-turbine configuration is represented in Figure 2(c) by red and blue rhombus respectively.

It is important to underline that the simulations have been carried out computing the filtration efficiency but avoiding the soot deposition since it would modify the porous medium geometry. Thus, the numerical stabilisation can be reached properly assessing the filtration efficiency of the DPF in clean or in a particular soot loading condition. Therefore, inlet and outlet soot flow cannot be applied as usual to compute the in-cycle averaged filtration efficiency of the DPF. As alternative, an equivalent definition taking into account the mass flow profile along the inlet channel is proposed. Thus the in-cycle averaged filtration efficiency of the DPF is calculated based on the in-cycle averaged filtration efficiency in every control volume weighed by the in-cycle averaged mass flow across each control volume and the total mass flow across the DPF as

$$
\bar{E}_{f_{D P F}}=\frac{\sum_{j}^{n} \bar{E}_{f_{C V_{j}}} \dot{m}_{w_{C V_{j}}}}{\sum_{j}^{n} \dot{m}_{w_{C V_{j}}}},
$$

where $n$ is the number of control volumes along the DPF channels.

\section{Results of the parametric study}

\subsection{Diameter variation}

\subsubsection{Clean DPF.}

According to the performed parametric study, Figure 3 represents the DPF filtration efficiency as a function of monolith volume and cell density for the baseline TIF under clean DPF conditions. Plots (a) and (b) are referred to pre- and post-turbine DPF configuration respectively. The computed cases are pointed out by black circles. White colour lines on the plot contour identify iso-filtration area regions.

Figure 3 shows that the ability of the filter to collect soot particles is directly related to the filtration area regardless the DPF placement: the higher the filtration area the higher the filtration efficiency. In absolute terms, pre-turbine DPF configuration provides higher DPF filtration efficiency than post-turbine one. In the baseline case, i.e. 2.431 in monolith volume and 200 cpsi in cell density, the pre-turbine DPF configuration leads to 0.52 in filtration efficiency, i.e. an increase of $21 \%$ with respect to the case of post-turbine DPF configuration. Approximately, pre-turbine DPF configuration provides an absolute increase of 10 percentage points in filtration efficiency in the analysed volume and cell density range. This difference brings the possibility in pre-turbine DPF configuration of reducing the monolith volume without any cell density variation up to 1.61 getting to the same filtration efficiency in clean DPF conditions than the post-turbine placement.

The reason for such filtration efficiency increase with pre-turbine DPF placement lies on the different flow field across the DPF monolith. Under clean conditions, the DPF filtration efficiency is mostly set by the Brownian diffusion 
contribution (Serrano et al. (2016)). This mechanism gets more efficient as the Peclet number decreases. Pre-turbine DPF placement contributes to such decrease because of the diffusion coefficient increase due to the higher gas temperature than in post-turbine case. In addition, the filtration velocity is also lower in most part of the cycle despite instantaneous fluctuations, as shown in Figure 2. Figure 4 confirms a relevant reduction of the Peclet number when the filter is placed upstream of the turbine thus justifying higher DPF filtration efficiency.

\subsubsection{Soot loaded DPF.}

Figure 5 shows the results in DPF filtration efficiency imposing a soot loading equal to $0.2 \mathrm{~g}$ thus avoiding the saturation of the porous wall in every monolith geometry. As expected the filtration efficiency is increased with respect to the clean filter. The main responsible of the filtration efficiency increase is found in the change of the porous wall microstructure. As a consequence of the soot accumulation the collector unit diameter increases and the wall porosity decreases with respect to the clean case as shown in Figure 6. This effect is independent on the DPF location so that no comparison between pre- and post-turbine configurations is shown.

The differences in the collector unit diameter value and porosity as a function of the monolith geometry shown in Figure 6 are related to the variation of the soot amount per unit of filtration area in every case due to the change of filtration area. At constant volume, the cell density increment increases the filtration area by means of the specific filtration area increment, according to equations 15 and 16 :

$$
\begin{gathered}
S F A=\frac{2 \alpha}{\left(\alpha+w_{w}\right)^{2}}=2 \alpha \sigma \\
A_{f}=S F A \frac{\pi D^{2}}{4} L_{e}
\end{gathered}
$$

In turn, the volume increment at constant cell density, i.e constant $S F A$, also involves a linear increment of filtration area. Therefore, the higher cell density and volume the higher the filtration area and as a result the smaller the collector unit diameter and the higher the porosity. It is relevant to note how the soot capacity of the DPF is not only related to volume, as usually simplified. Figure 6 shows that the filtration area, i.e. the combination of volume and cellular geometry, is actually the governing parameter. Constant filtration area iso-lines coincides with constant collector unit diameter and porosity.

As stated in equations 5 and 6, the porous wall microstructure directly impacts on the single sphere interception efficiency. In parallel, the changes in the microstructure also favour the increase of the packed bed efficiency according to equation 10. Thus, the collector unit diameter increment and the porosity decrease produce the increment of the DPF interception efficiency, as represented in Figure 7. It can be noted how the order of magnitude of this contribution to the DPF filtration efficiency is similar to the DPF filtration efficiency in clean conditions. In addition, these effects are independent on the DPF location since the interception mechanism is just depending on the micro-geometry.

Figure 8 represents the effect of the soot loading on the Peclet number. Comparing with Figure 4, it is clearly noticed the increase of the Peclet number in the whole analysed range. Such a Peclet number increase is governed 
by the microstructure variations despite the reduction in filtration velocity because of the pressure increment, i.e. gas density increment. In particular, the higher filtration velocity in post-turbine DPF placement makes the Peclet number in this location also higher than the obtained by the pre-turbine DPF configuration.

Despite the noticeable Peclet number increment, Figure 9 shows that the DPF filtration efficiency exclusively due to Brownian diffusion contribution increases because of the microstructure variation. In fact, the obtained value is higher than these of the DPF filtration efficiency in clean conditions shown in Figure 3 and the penalty related to the volume and cell density reduction results much more limited.

As expected, even very low soot loading produces a sharp increment of the DPF filtration efficiency. However, such an increment is particularly relevant in the small volume and low cell density range because of the maximum interception filtration efficiency together with the more homogeneous Brownian diffusion contribution with respect to clean conditions. As a result the DPF filtration efficiency becomes quite homogeneous in the whole range. The DPF filtration efficiency and its homogeneity as a function of the soot loading are to increase as the soot loading does.

\subsection{Length variation}

\subsubsection{Clean DPF.}

Figure 10 shows the DPF filtration efficiency as a function of the monolith volume and cell density in clean DPF conditions when the volume reduction is governed by the monolith length decrease. The profile of DPF filtration efficiency is almost identical to that obtained by the monolith diameter reduction as confirmed by comparing plots (a) and (b) for pre- and post-turbine DPF placement with the respective ones in Figure 3.

Decreasing the volume keeping constant the cell density, i.e. moving horizontally in the contour plots, has again a damaging effect on the clean DPF filtration efficiency. Figure 11(a) shows the effect of the volume reduction keeping constant the baseline cell density (200 cpsi) on the filtration velocity along the monolith length in the case of pre-turbine DPF configuration. It can be noted a linear increment of the filtration velocity because of the volume reduction as well as an increment towards the channel end. These effects produce an increment of the local Peclet number with the same fashion according to equation 1. As stated before concerning diameter reduction the Brownian diffusion mechanism is the dominant one; its inverse dependence on the Peclet number results in a decrease of the probability of a particle to get stuck on a collector unit as the filtration velocity increases.

Despite the similar profile of DPF filtration efficiency regardless diameter or length reduction to meet volume requirements, length reduction strategy leads to slightly lower filtration efficiency close to $-1 \%$ in absolute reference. These small deviations are related to the different filtration velocity field. Figure 11(b) shows the filtration velocity along the inlet channels length for the minimum volume and baseline cell density both for diameter and length reduction. Most of the mass flow is subjected to higher filtration velocity in the case of length reduction what penalises the Brownian diffusion mechanism. However in the diameter case, the sharp filtration velocity in the rear part of the inlet channels produces a local penalty because of the high mass flow across the porous wall in this region. Consequently this region becomes very damaging in the calculation of the average DPF filtration efficiency. As a result, the differ- 
ence in the DPF filtration efficiency is minimum between the two volume reduction strategies. Similar behaviour is found as the cell density is increased. Figure 11(c) shows how the increase of filtration area leads to very different trend in filtration velocity in comparison to Figure 11(b). Maximum local filtration velocity is similar for diameter or length reduction, but the minimum filtration velocity is clearly lower in a long region of the inlet channels. This behaviour explains the increase of the DPF filtration efficiency when the cell density does because of the higher weight of the low filtration velocity region. Nevertheless, the slight damage of the length reduction against diameter reduction remains.

\subsubsection{Soot loaded DPF.}

Figure 12 shows the DPF filtration efficiency as a function of cell density and volume variation when the soot loading is $0.2 \mathrm{~g}$. This case combines the effects of soot loading and monolith length previously discussed. Soot loading makes the DPF filtration efficiency to increase mainly because of the higher collector unit diameter and the lower porosity. In parallel, the length reduction leads to higher filtration velocity than the diameter strategy comparing at the same volume. However, diameter reduction produces a more heterogeneous filtration velocity field along the inlet channels. Consequently, the DPF filtration efficiency is only slightly lower applying length reduction strategy than volume definition based on diameter variation.

\section{Approach to volume reduction analysis}

Two basic strategies can be approached in order to get further understanding of the macro-and meso-geometry influence on the DPF performance: volume reduction at constant specific filtration area and volume reduction at constant filtration area. Additionally, it allows easily discussing the TIF variation effect.

\subsection{Constant specific filtration area}

The variation of volume at constant specific filtration area keeping TIF also constant leads to constant cell size and porous wall thickness (Serrano et al. (2014a)). Consequently, all cell unit geometric parameters, such as cell density, OFA, LOF, HTP (without Nu influence), MIF and STP, are also kept constant. Therefore, the DPF performance is only determined by the macro-geometry change in volume (diameter and length variation), which in turn sets the filtration area.

Figure 13 shows the filtration efficiency as the monolith volume is reduced at constant SFA for three different TIF values. As cell density is kept constant with this approach, the baseline value (200 cpsi) has been selected. Constant SFA approach makes the DPF filtration efficiency very sensitive to volume, being damaged as volume is reduced. This is particularly relevant in clean conditions and also observed in the considered soot loading case. Reasons related to the fluid-dynamic field and micro-geometry (change from clean to soot loading conditions) have been discussed in Section 3f. However, it is interesting to note that at constant volume higher DPF filtration efficiency is always obtained by pre-turbine DPF configuration. It ensures lower particulate matter emissions before the maximum DPF 
filtration efficiency is reached. In addition, constant SFA approach allows reaching maximum volume decrease with pre-turbine DPF configuration providing the same filtration efficiency than the baseline volume in post-turbine DPF placement.

With respect to TIF, it is clearly observed that its influence within the whole range is very slight. The variations are related to small change in filtration area. Keeping the baseline cell density and according to equation 12, TIF increment is given by the same percentage of porous wall thickness decrease and cell size increment. As a consequence SFA is increased, i.e. wider channels at constant cell density means more contact surface between the gas and the porous substrate. Therefore, the filtration area is also increased thus leading to increase the Brownian diffusion contribution to particles collection because of the filtration velocity reduction.

As the DPF is loaded the TIF effect becomes negligible progressively because of the growing importance of the microstructure. This result points out that TIF definition must be dependent on pressure drop performance, i.e. specific fuel consumption, together with other structural criteria such as MIF or STP (Serrano et al. (2014a)).

\subsection{Constant filtration area}

In contrast to constant specific filtration area, constant filtration area approach requires to increase cell density if TIF is kept constant as the volume is reduced (Serrano et al. (2014a)). Similarly, LOF and HPT also show an increase dependent on the volume variation whilst OFA, MIF and STP remain constant. Although cell density increment as the volume is reduced may lead to channel plugging issues, benefits in pressure drop are found (Serrano et al. (2014a)). In addition, Figure 14 shows that this approach avoids any penalty on the DPF filtration efficiency related to DPF volume reduction. Only a slight decrease is observed in the case of monolith length reduction. It is because of the filtration velocity profile along the inlet channel, as explained in Section 3.2. Remainder variables, i.e. TIF, DPF placement and loading show the same trends than in constant SFA approach.

\section{Summary and conclusions}

A computational study on the impact of the DPF geometry on the filtration efficiency has been presented in this paper. The study has covered the influence of the monolith volume reduction dictated by diameter and length variations. In addition, the macro-geometry change has been combined with a swept in the cellular geometry in order to account for the effect of the meso-geometry under the restriction of constant TIF. The results have been analysed comparing the behaviour of post-turbine and pre-turbine DPF configurations as well as considering clean and low soot loading conditions.

Pre-turbine DPF configuration provides higher filtration efficiency both for clean and low soot loading than postturbine location. This is due to the lower Peclet number upstream of the turbine. As a consequence, tailpipe emitted particle mass and number before convergence to maximum filtration efficiency would be lower in pre-turbine DPF configurations. The profile of DPF filtration efficiency as a function of the monolith volume and cell density is the 
same regardless diameter or length reduction to meet volume requirements. Nevertheless, absolute value is slightly higher when volume is obtained based on diameter reduction. It is due to the differences in the filtration velocity field along the monolith channels.

The known potential for DPF downsizing of pre-turbine DPF configuration based on fluid-dynamic criteria (engine fuel economy reduction) is strengthened by the fact that the monolith volume can be reduced around $40 \%$ within a wide range of meso-geometry definitions improving the filtration performance with respect to post-turbine placement. Volume reduction at constant specific area, i.e. constant cell density, provides reduction in filtration efficiency as volume does but the resulting value in pre-turbine case is still higher than the baseline one in post-turbine location. TIF is shown to be a second-order parameter on filtration efficiency and must be set based on pressure drop and thermal resistance criteria. Consequently, this kind of strategy keeps the original DPF filtration performance with improvements in pressure drop (bsfc) and cost-savings in materials. The opposed strategy is to reduce the monolith volume keeping constant the filtration area at the same time TIF is also kept. This means that the cell density must be increased. The advantage is that the filtration efficiency keeps the same value as in baseline volume, both in pre- and post-turbine DPF placement. It is added to the benefits in pressure drop related to constant filtration area. However, cell density increment as the volume is reduced may lead to channel plugging issues specially in post-turbine configuration. Hence the current state of the art defining the monolith size in post-turbine applications. Nevertheless, pre-turbine DPF configuration provides higher ability to avoid channel plugging because of the expected low soot loading related to the higher temperature (passive regeneration). According to pressure drop sizing criteria, a balance solution between constant specific filtration area and constant filtration area as the volume is reduced with pre-turbine placement exists at the same time that improvements in filtration efficiency are obtained.

\section{Acknowledgements}

This work has been partially supported by the Spanish Ministry of Economy and Competitiveness through Grant No. TRA2013-40853-R. Additionally, the Ph.D. student E. Angiolini has been funded by a grant from Conselleria de Educació, Cultura i Esport of the Generalitat Valenciana with reference GRISOLIA/2013/036. These supports are gratefully acknowledged by the authors.

Bermúdez, V., Serrano, J. R., Piqueras, P., \& García-Afonso, O. (2013). Analysis of heavy-duty turbocharged Diesel engine response under cold transient operation with a pre-turbo aftertreatment exhaust manifold configuration. International Journal of Engine Research, 14, 341-353.

Blanchard, G., Colignon, C., Griard, C., Rigaudeau, C., Salvat, O., \& Seguelong, T. (2002). Passenger car series application of a new diesel particulate filter system using a new Ceria-based fuel-borne catalyst: from the engine test bench to European vehicle certification. In $S A E$ Technical Paper 2002-01-2781.

Bollerhoff, T., Markomanolakis, I., \& Koltsakis, G. (2012). Filtration and regeneration modeling for particulate filters with inhomogeneous wall structure. Catalysis Today, 188, 24-31.

Brüstle, C., Downey, M., Subramaniam, M. N., Birckett, A., \& Tomazic, D. (2011). Aftertreatment in a pre-turbo position: size and fuel consumption advantage for Tier 4 large-bore Diesel engines. In Aachen Colloquium Automobile and Engine Technology 2011.

Burtscher, H. (2005). Physical characterization of particulate emissions from Diesel engines: a review. Journal of Aerosol Science, 36, 896-932. 
Depcik, C. D., \& Hausmann, A. J. (2013). Review and a methodology to investigate the effects of monolithic channel geometry. Journal of Engineering for Gas Turbine and Power, 135, 032301 1-16.

Desantes, J. M., Serrano, J. R., Arnau, F. J., \& Piqueras, P. (2012). Derivation of the method of characteristics for the fluid dynamic solution of flow advection along porous wall channels. Applied Mathematical Modelling, 36, 3144-3152.

EPA (2000). Regulatory impact analysis: control of emissions of air pollution from highway Heavy-Duty engines. U.S. Environmental Protection Agency (EPA) - Office of Transportation and Air Quality.

EPA, \& NHTSA (2010). Final rulemaking to establish light-duty vehicle greenhouse gas emission standards and corporate average fuel economy standards, Joint Technical Support Document.. U.S. Environmental Protection Agency (EPA) and U.S. National Highway Traffic Safety Administration (NHTSA).

Ferrel, W. (1971). An introduction to probability theory and its applications. Wiley, New York.

Fino, D., Russo, N., Millo, F., Vezza, D., Ferrero, F.,\& Chianale, A. (2009). New tool for experimental analysis of diesel particulate filter loading. Top Catalysis, 52, 13-20.

Galindo, J., Serrano, J. R., Arnau, F. J., \& Piqueras, P. (2009). Description of a semi-independent time discretization methodology for a onedimensional gas dynamics model. Journal of Engineering for Gas Turbines and Power, 131, 034504.

Galindo, J., Serrano, J. R., Piqueras, P., \& García-Afonso, O. (2012). Heat transfer modelling in honeycomb wall-flow diesel particulate filters. Energy, 43, 201-213.

Gong, J., \& Rutland, C. J. (2015). PDF-based heterogeneous multiscale filtration model. Environmental Science E Technology, 49(8), 4963-4970.

Guan, B., Zhan, R., Lin, H. \& Huang, Z. (2015). Review of the state-of-the-art of exhaust particulate filter technology in internal combustion engines. Journal of Environmental Management, 154, 225-258.

Hanamura, K., Karin, P., Cui, L., Rubio, P., Tsuruta, T., Tanaka, T., \& Suzuki, T. (2009). Micro- and macroscopic visualization of particulate matter trapping and regeneration processes in wall-flow diesel particulate filters. International Journal of Engine Research, 10, 305-321.

Jiang, J., Gong, J., Liu, W., Chen, T., \& Zhong, C. (2016). Analysis on filtration characteristic of wall-flow filter for ash deposition in cake. Journal of Aerosol Science, 95, 73-83.

Johnson, T. V. (2009). Review of diesel emissions and control. International Journal of Engine Research, 10, 275 -285.

Kai, R., Sekiya, T., Ogawa, M., Saiki, K., Matsubara, R., Kurachi, H., Brayer, M., Warner, E., Fujii, S., \& Ren, S. (2009). Thermal-mechanical durability of DOC and DPF aftertreatment system for light heavy pickup truck application. In SAE Technical Paper 2009-01-2707.

Kittelson, D. (1998). Engines and nanoparticles, a review. Journal of Aerosol Science, 29, 575-588.

Konstandopoulos, A. G., \& Johnson, J. H. (1989). Wall-flow diesel particulate filters - Their pressure drop and collection efficiency. In SAE Technical Paper 890405.

Konstandopoulos, A., \& Kladopoulou, E. (2004). The optimum cell density for wall-flow monolithic filters: effects of filter permeability, soot cake structure and ash loading. In SAE Technical Paper 2004-01-1133.

Konstandopoulos, A. G., Skaperdas, E., Warren, J., \& Allansson, R. (1999). Optimized filter design and selection criteria for continuously regenerating diesel particulate traps. In SAE Technical Paper 1999-01-0468.

Lee, K. W., \& Gieseke, J. A. (1979). Collection of aerosol particles by packed beds. Environmental Science E Technology, 13, 466-470.

Lee, S. J., Jeong, S. J., \& Kim, W. S. (2009). Numerical design of the diesel particulate filter for optimum thermal performances during regeneration. Applied Energy, 86, 1124-1135.

Liu, Y., Gong, J., Fu, J., Cai, H., \& Long, G. (2009). Nanoparticle motion trajectories and deposition in an inlet channel of wall-flow diesel particulate filter. Journal of Aerosol Science, 40, 307-323.

Logan, B. E., Jewett, D. G., Arnold, R. G., Bouwer, J., \& O’Melia, C. R. (1995). Clarification of clean-bed filtration models. Journal of Environmental Engineering, 121, 869-873.

Lújan, J. M., Bermúdez, V., Piqueras, P., \& García-Afonso, O. (2015a). Experimental assessment of pre-turbo aftertreatment configurations in a single stage turbocharged Diesel engine. Part 1: Steady-state operation. Energy, 80, 599-613. 
Lújan, J. M., Serrano, J. R., Piqueras, P., \& García-Afonso, O. (2015b). Experimental assessment of a pre-turbo aftertreatment configuration in a single stage turbocharged Diesel engine. Part 2: Transient operation. Energy, 80, 614-627.

Mamakos, A., Martini, G., Marotta, A., \& Manfredi, U. (2013a). Assessment of different technical options in reducing particle emissions from gasoline direct injection vehicles. Journal of Aerosol Science, 63, 115-125.

Mamakos, A., Steininger, N., Martini, G., Dilara, P., \& Drossinos, Y. (2013b). Cost effectiveness of particulate filter installation on direct injection gasoline vehicles. Atmospheric Environment, 77, 16-23.

Merkel, G. A., Beall, D. M., Hickman, D. L., \& Vernacotola, M. J. (2001). Effects of microstructure and cell geometry on performance of cordierite diesel particulate filters. In SAE Technical Paper 2001-01-0193.

NAS (2011). Assessment of fuel economy technologies for light-duty vehicles. U.S. National Academy of Sciences.

Official Journal of the European Union (2007). Regulation (EC) no 715/2007 of the European Parliament and of the Council of 20 June 2007 on type approval of motor vehicles with respect to emissions from light passenger and commercial vehicles (Euro 5 and Euro 6) and on access to vehicle repair and maintenance information.

OpenWAM (2016). Openwam website, CMT-Motores Térmicos (Universitat Politécnica de Valéncia). www.openwam.org. Accessed 30.06.2016.

Payri, F., Broatch, A., Serrano, J. R., \& Piqueras, P. (2011). Experimental-theoretical methodology for determination of inertial pressure drop distribution and pore structure properties in wall-flow diesel particulate filters (DPFs). Energy, 36, 6731-6744.

Posada, F., Bandivadekar, A., \& German, J. (2013). Estimated cost of emission control technologies for light-duty vehicles. Part 2 - Diesel. In SAE Technical Paper 2013-01-0539.

Rosner, D. E., \& Tandon, P. (1995). Rational prediction of inertially-induced particle deposition rates on a cylindrical target in dust-laden. Chemical Engineering Science, 50(21), 3409-3431.

Serrano, J. R., Climent, H., Piqueras, P., \& Angiolini, E. (2014a). Analysis of fluid-dynamic guidelines in diesel particulate filter sizing for fuel consumption reduction in post-turbo and pre-turbo placement. Applied Energy, 132, 507-523.

Serrano, J. R., Arnau, F. J., Piqueras, P., \& García-Afonso, O. (2013). Packed bed of spherical particles approach for pressure drop prediction in wall-flow DPFs (diesel particulate filters) under soot loading conditions. Energy, 58, 644-654.

Serrano, J. R., Climent, H., Piqueras, P., \& Angiolini, E. (2016). Filtration modelling in wall-flow particulate filters of low soot penetration thickness. Energy, 883-898.

Serrano, J. R., Guardiola, C., Piqueras, P., \& Angiolini, E. (2014b). Analysis of the aftertreatment sizing for pre-turbo DPF and doc exhaust line configuration. In SAE Technical Paper 2014-01-1498.

Torregrosa, A. J., Serrano, J. R., Arnau, F. J., \& Piqueras, P. (2011). A fluid dynamic model for unsteady compressible flow in wall-flow diesel particulate filters. Energy, 36, 671-684.

\section{Nomenclature}
$A_{f} \quad$ filtration area
$b s f c \quad$ brake specific fuel consumption
$d_{c, w} \quad$ porous wall collector unit diameter
$d_{\text {part }} \quad$ particle diameter
D diameter
$D_{p} \quad$ diffusion coefficient
DOC Diesel Oxidation Catalyst
DPF Diesel Particulate Filter 


$\begin{array}{ll}\bar{E}_{f} & \text { in-cycle averaged filtration efficiency } \\ f_{w} & \text { penetrated fraction of porous wall thickness } \\ \text { HTP } & \text { bulk Heat Transfer Parameter } \\ k_{B} & \text { Boltzmann constant } \\ K & \text { Kuwabara's hydrodynamic factor } \\ L_{e} & \text { channel length } \\ L O F & \text { Light-Off Factor } \\ \dot{m}_{w} & \text { mass flow across the porous wall } \\ \text { MIF } & \text { Mechanical Integrity Factor } \\ n & \text { number of control volumes in DPF channels } \\ N_{R} & \text { interception parameter } \\ \text { OFA } & \text { Open Frontal Area } \\ P e & \text { Peclet number } \\ \text { PSD } & \text { Particle Size Distribution } \\ Q & \text { volumetric flow rate } \\ S_{c} & \text { sticking coefficient } \\ \text { SCF } & \text { Stokes-Cunningham Factor } \\ \text { SCR } & \text { Selective Catalytic Reduction } \\ \text { SFA } & \text { Specific Filtration Area } \\ S t & \text { Stokes number } \\ \text { STP } & \text { Strain Tolerance Parameter } \\ t_{c} & \text { engine cycle duration } \\ \text { TIF } & \text { Thermal Integrity Factor } \\ u_{i, w} & \text { interstitial velocity } \\ u_{w} & \end{array}$

\section{Greek letters}

$\begin{array}{ll}\Delta t & \text { time-step } \\ \varepsilon_{w} & \text { porous wall porosity } \\ \mu & \text { dynamic viscosity } \\ \eta_{D} & \text { single sphere diffusion collection efficiency } \\ \eta_{R} & \text { single sphere interception collection efficiency }\end{array}$




$$
\begin{array}{ll}
\eta_{I} & \text { single sphere inertial collection efficiency } \\
\eta_{D R I} & \text { single sphere global collection efficiency } \\
\rho_{s, w} & \text { soot density inside the porous wall } \\
\sigma & \text { cell density }
\end{array}
$$

\section{Subscripts}

CV control volume

$D P F \quad$ related to the whole DPF

$i \quad$ index for every particle diameter

$j \quad$ index for every control volume

mec collection mechanism

w related to porous wall

\section{List of Tables}

- Table 1.- Main engine characteristics.

- Table 2.- Baseline DPF characteristics.

\section{List of Figures}

- Figure 1.- Comparison between experimental data and modelled results with post- and pre-turbine aftertreatment configurations.

- Figure 2.- Profile of filtration velocity and efficiency in post- and pre-turbine DPF configuration with baseline DPF in clean conditions.

- Figure 3.- DPF filtration efficiency as a function of monolith volume and cell density for baseline TIF and clean DPF conditions. Volume reduction defined by diameter reduction.

- Figure 4.- Peclet number across the porous wall as a function of monolith volume and cell density for baseline TIF and clean DPF conditions. Volume reduction defined by diameter reduction.

- Figure 5.- DPF filtration efficiency as a function of monolith volume and cell density for baseline TIF and soot loading conditions. Volume reduction defined by diameter reduction.

- Figure 6.- Porous wall microstructure as a function of monolith volume and cell density for baseline TIF and soot loading conditions. Volume reduction defined by diameter reduction.

- Figure 7.- DPF interception filtration efficiency as a function of monolith volume and cell density for baseline TIF and soot loading conditions. Volume reduction defined by diameter reduction.

- Figure 8.- Peclet number across the porous wall as a function of monolith volume and cell density for baseline TIF and soot loading conditions. Volume reduction defined by diameter reduction. 
- Figure 9.- DPF Brownian diffusion filtration efficiency as a function of monolith volume and cell density for baseline TIF and soot loading conditions. Volume reduction defined by diameter reduction.

- Figure 10.- DPF filtration efficiency as a function of monolith volume and cell density for baseline TIF and clean DPF conditions. Volume reduction defined by length reduction.

- Figure 11.- Impact of volume definition strategy and cell density on filtration velocity with pre-turbine DPF configuration.

- Figure 12.- DPF filtration efficiency as a function of monolith volume and cell density for baseline TIF and soot loading conditions. Volume reduction defined by length reduction.

- Figure 13.- Effect of volume, TIF, placement and soot loading on the DPF filtration efficiency with constant SFA.

- Figure 14.- Effect of volume, TIF, placement and soot loading on the DPF filtration efficiency with constant filtration area. 
Table 1: Main engine characteristics.

\begin{tabular}{ll}
\hline \hline Type & HSDI E4 Diesel engine \\
Displacement & $1997 \mathrm{~cm}^{3}$ \\
Diameter & $85 \mathrm{~mm}$ \\
Stroke & $88 \mathrm{~mm}$ \\
Number of cylinders & 4 in line \\
Valves & 4 per cylinder \\
Compression ratio & $18: 1$ \\
Maximum power & $100 \mathrm{~kW}$ at $4000 \mathrm{rpm}$ \\
Maximum torque & $320 \mathrm{Nm}$ at $1750 \mathrm{rpm}$ \\
Turbocharger & Single-stage VGT \\
\hline \hline
\end{tabular}

Table 2: Baseline DPF characteristics.

\begin{tabular}{lcc}
\hline \hline Diameter & {$[\mathrm{mm}]$} & 135 \\
Length & {$[\mathrm{mm}]$} & 170 \\
Plug length & {$[\mathrm{mm}]$} & 5 \\
Monolith volume & {$[1]$} & 2.43 \\
Porosity & {$[-]$} & 0.46 \\
Mean pore diameter & {$[\mu \mathrm{m}]$} & 14.4 \\
Porous wall permeability & {$\left[\mathrm{m}^{2}\right]$} & $3.8 \times 10^{-13}$ \\
Cellular geometry & & Square \\
Honeycomb cell size & {$[\mathrm{mm}]$} & 1.47 \\
Wall thickness & {$[\mathrm{mm}]$} & 0.32 \\
Filtration area & {$\left[\mathrm{m}^{2}\right]$} & 2.17 \\
No of channels & {$[-]$} & 4470 \\
SFA & {$[1 / \mathrm{m}]$} & 917.6 \\
Cell density & {$[\mathrm{cpsi}]$} & 200 \\
TIF & {$[-]$} & 5.59 \\
\hline \hline
\end{tabular}




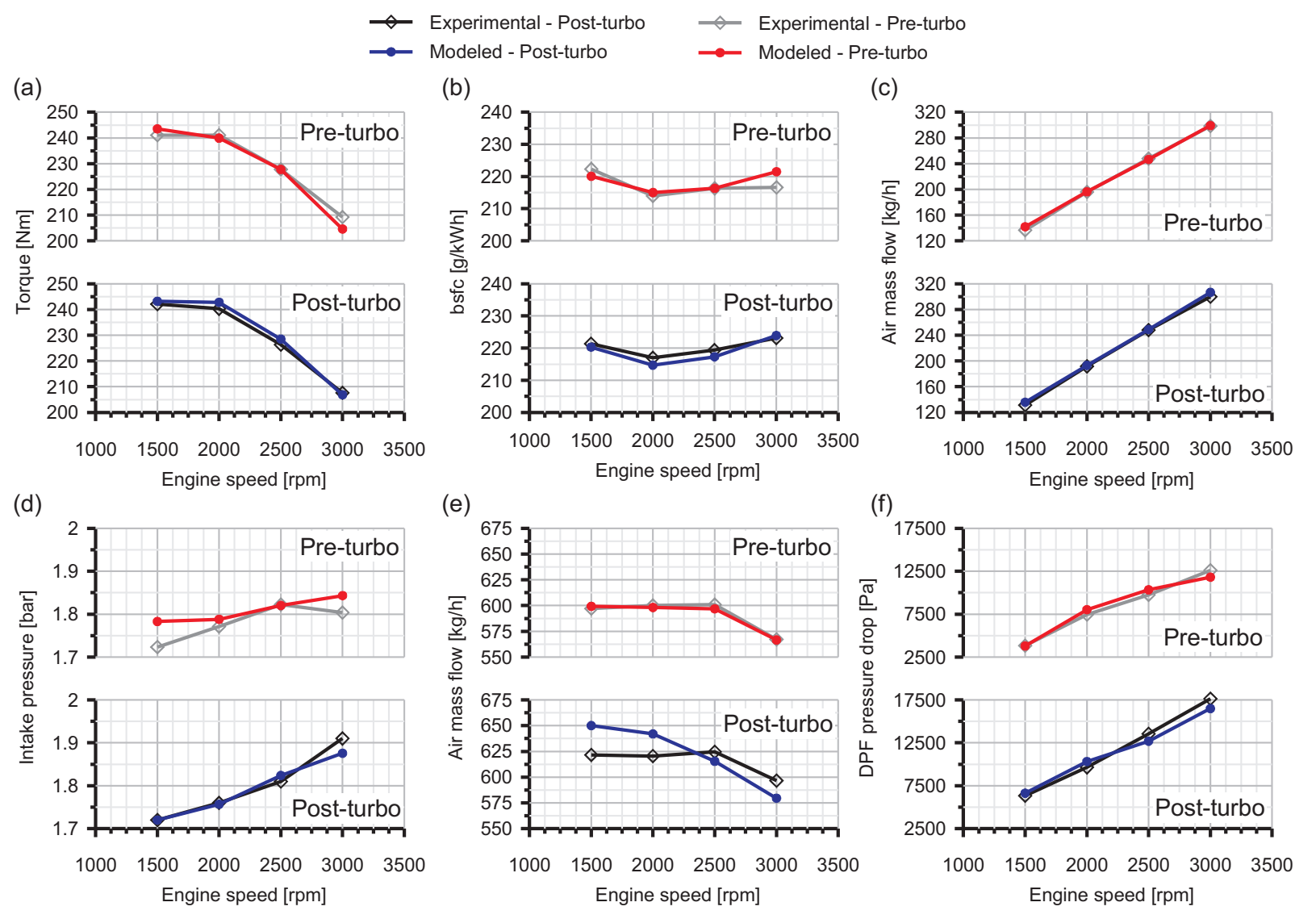

Figure 1: Comparison between experimental data and modelled results with post- and pre-turbine aftertreatment configurations.

(a)

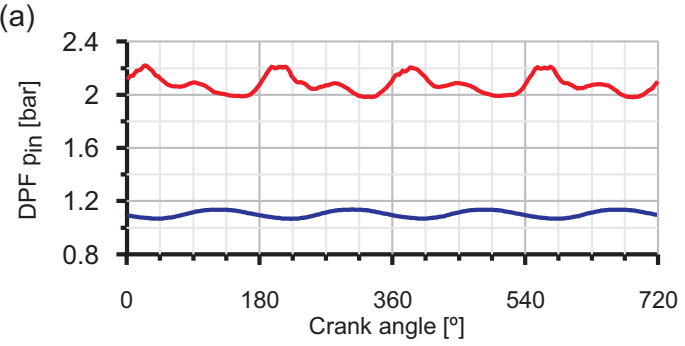

(c

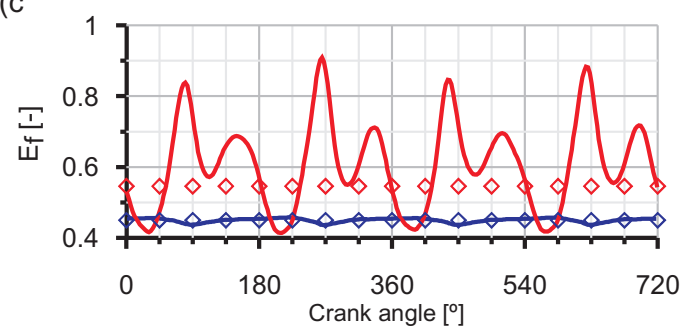

(b)

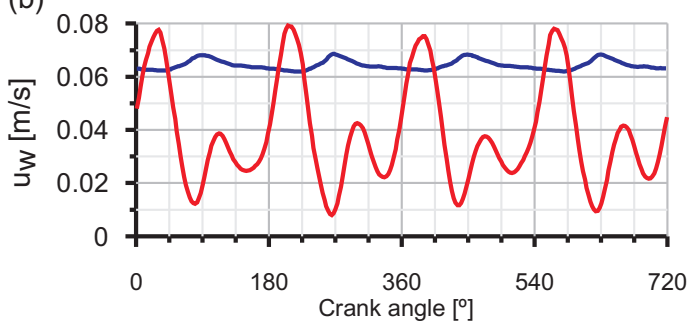

_ Pre-turbine

—_ Post-turbine

$\diamond \diamond \diamond$ In-cycle averaged

Instantaneous

Figure 2: Profile of filtration velocity and efficiency in post- and pre-turbine DPF configuration with baseline DPF in clean conditions. 
(a) Pre-turbine DPF filtration efficiency [-]

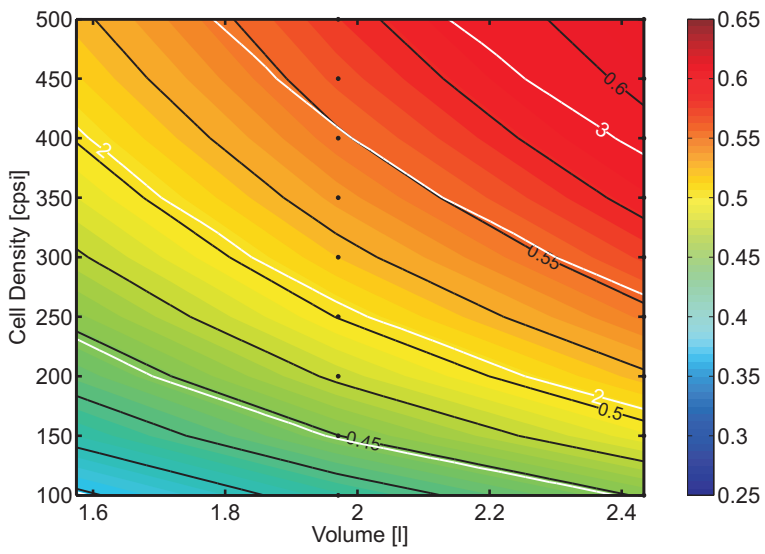

(b) Post-turbine DPF filtration efficiency [-]

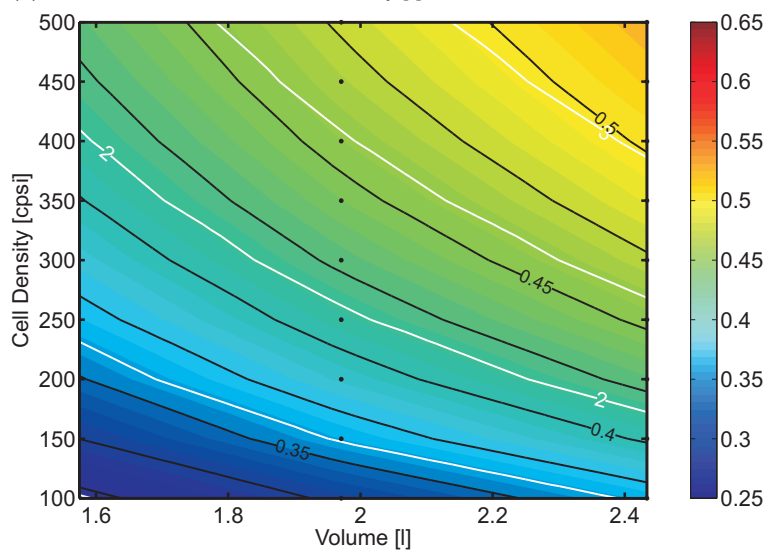

Figure 3: DPF filtration efficiency as a function of monolith volume and cell density for baseline TIF and clean DPF conditions. Volume reduction defined by diameter reduction.

(a) Pre-turbine Peclet number [-]

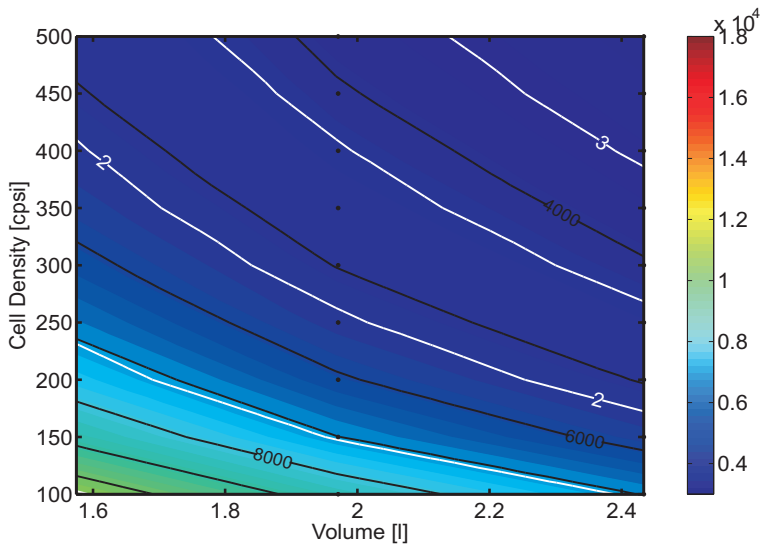

(b) Post-turbine Peclet number [-]

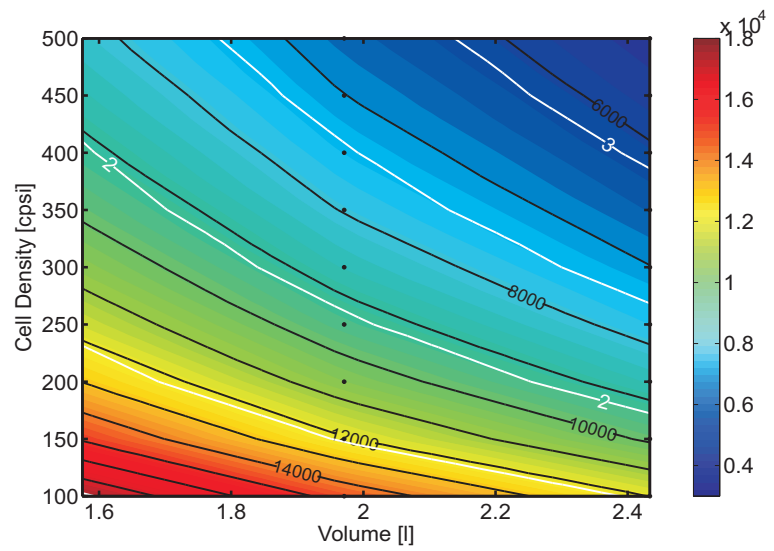

Figure 4: Peclet number across the porous wall as a function of monolith volume and cell density for baseline TIF and clean DPF conditions. Volume reduction defined by diameter reduction. 
(a) Pre-turbine DPF filtration efficiency [-]

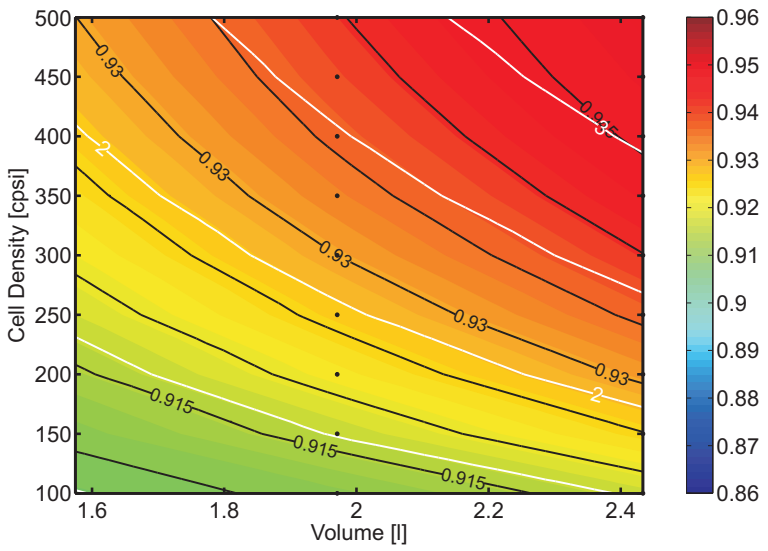

(b) Post-turbine DPF filtration efficiency [-]

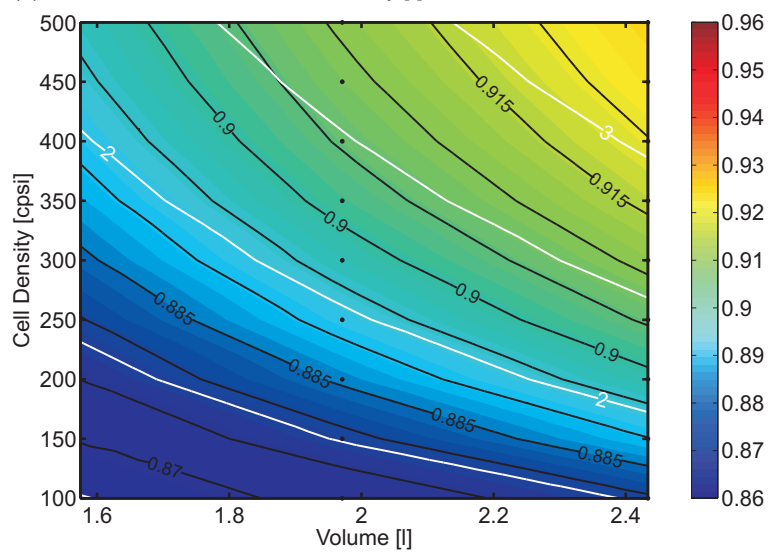

Figure 5: DPF filtration efficiency as a function of monolith volume and cell density for baseline TIF and soot loading conditions. Volume reduction defined by diameter reduction.

(a) Collector unit diameter [mm]

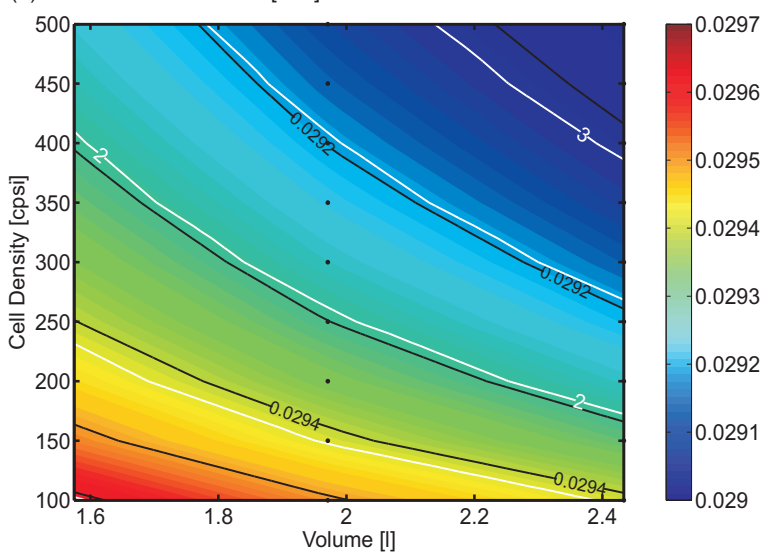

(b) Porosity [-]

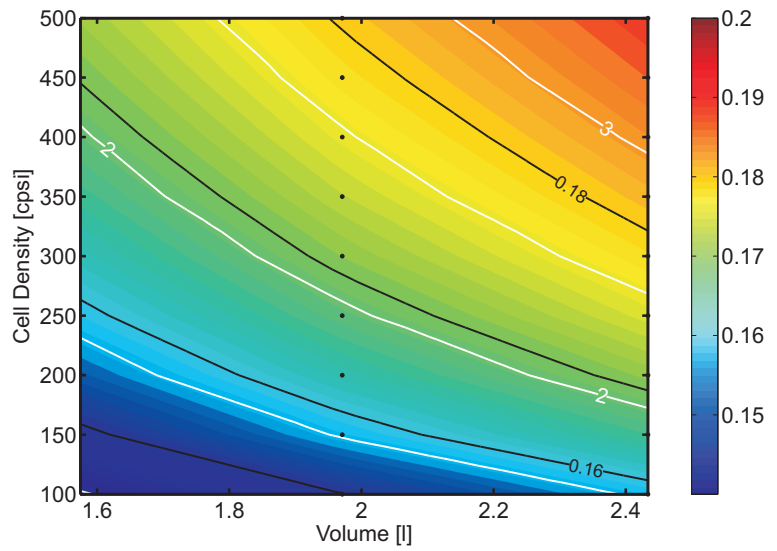

Figure 6: Porous wall microstructure as a function of monolith volume and cell density for baseline TIF and soot loading conditions. Volume reduction defined by diameter reduction. 


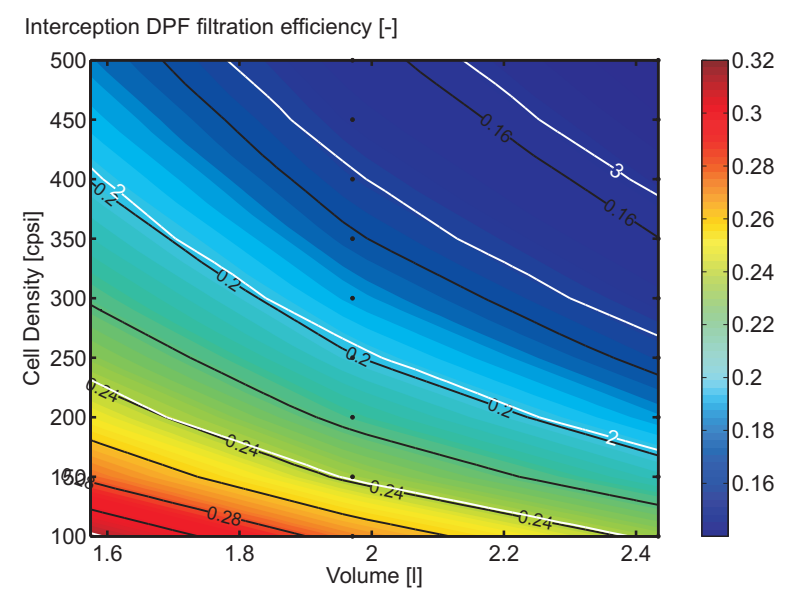

Figure 7: DPF interception filtration efficiency as a function of monolith volume and cell density for baseline TIF and soot loading conditions. Volume reduction defined by diameter reduction.

(a) Pre-turbine Peclet number [-]

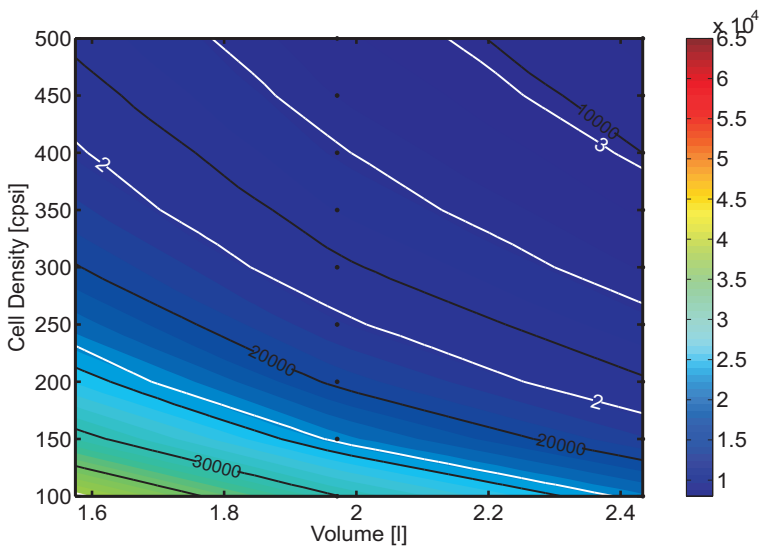

(b) Post-turbine Peclet number [-]

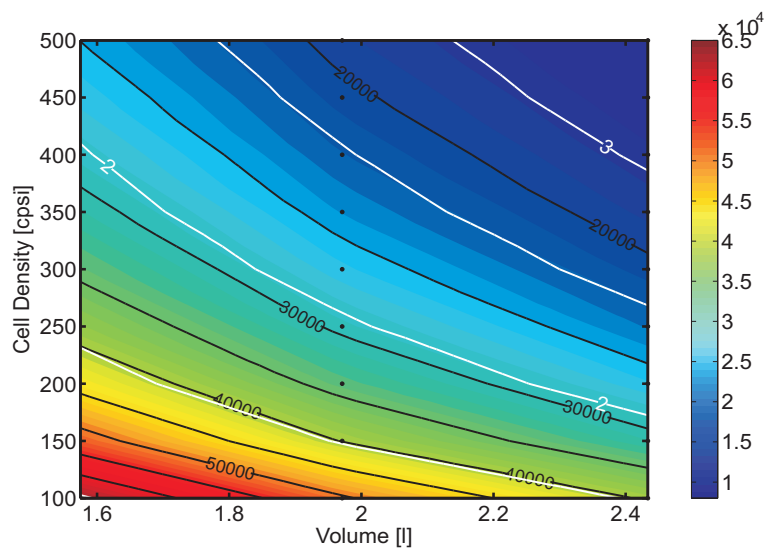

Figure 8: Peclet number across the porous wall as a function of monolith volume and cell density for baseline TIF and soot loading conditions. Volume reduction defined by diameter reduction. 
(a) Pre-turbine DPF Brownian diffusion filtration efficiency [-]

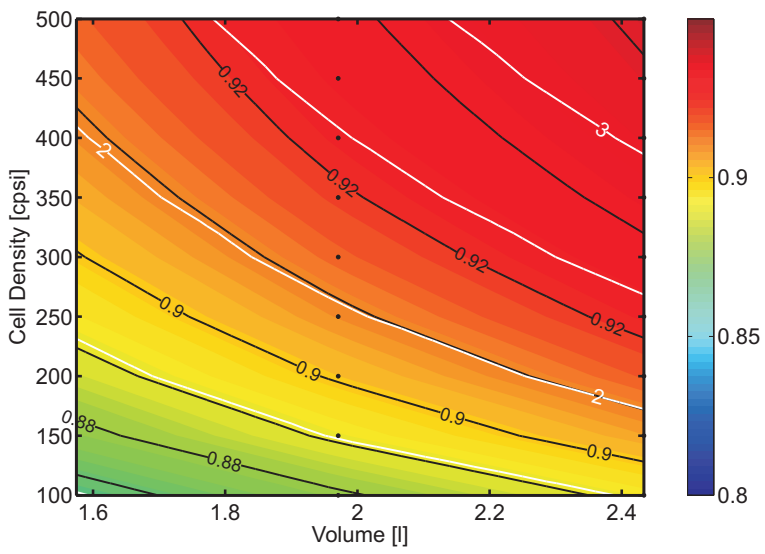

(b) Post-turbine DPF Brownian diffusion filtration efficiency [-]

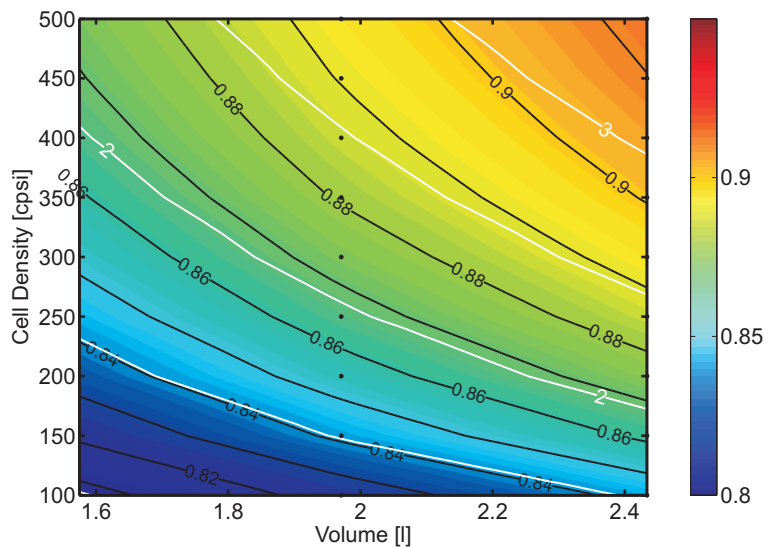

Figure 9: DPF Brownian diffusion filtration efficiency as a function of monolith volume and cell density for baseline TIF and soot loading conditions. Volume reduction defined by diameter reduction.

(a) Pre-turbine DPF filtration efficiency [-]

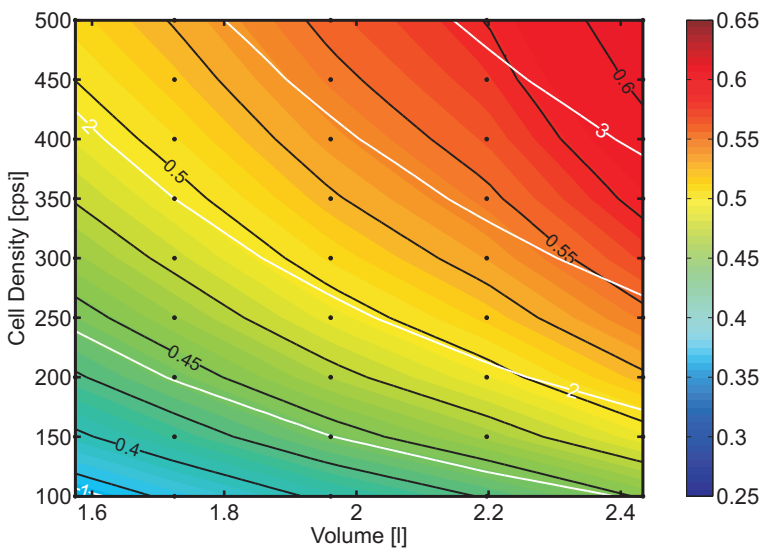

(b) Post-turbine DPF filtration efficiency [-]

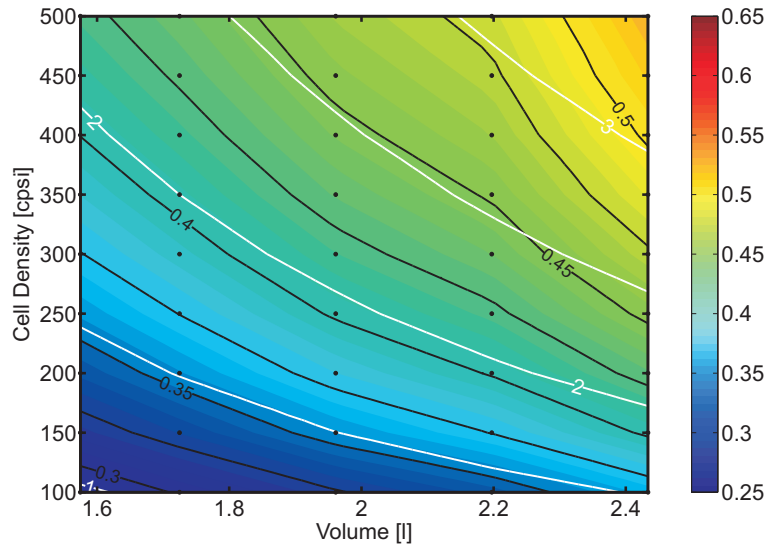

Figure 10: DPF filtration efficiency as a function of monolith volume and cell density for baseline TIF and clean DPF conditions. Volume reduction defined by length reduction. 
(a) Length reduction @ $\sigma=200 \mathrm{cpsi}$

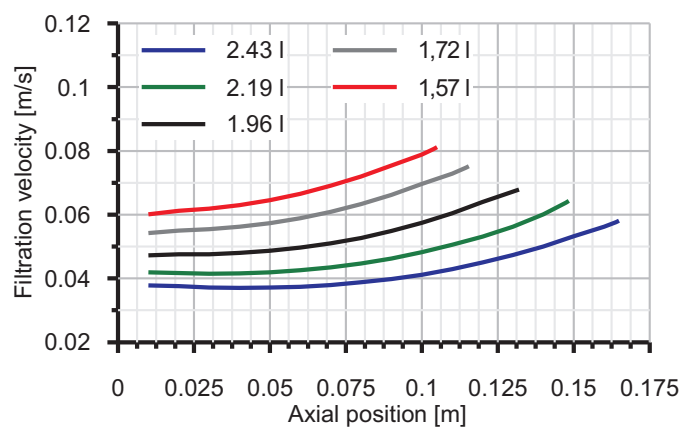

(b) V=1,57 I @ $\sigma=200 \mathrm{cpsi}$

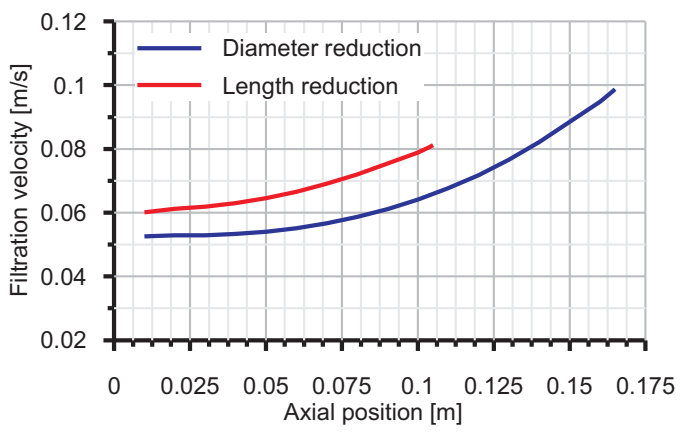

(c) $\mathrm{V}=1,57 \mathrm{I} @ \sigma=500 \mathrm{cpsi}$

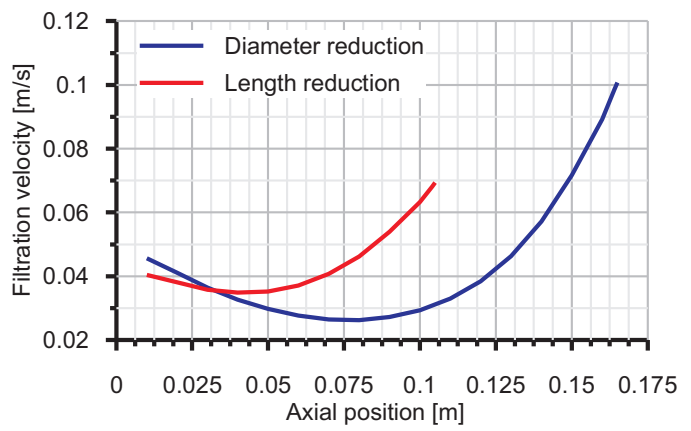

Figure 11: Impact of volume definition strategy and cell density on filtration velocity with pre-turbine DPF configuration.

(a) Pre-turbine DPF filtration efficiency [-]

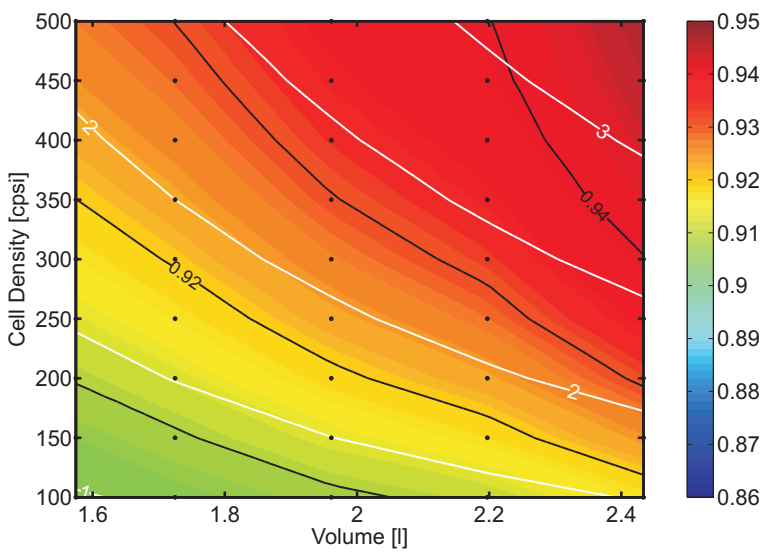

(b) Post-turbine DPF filtration efficiency [-]

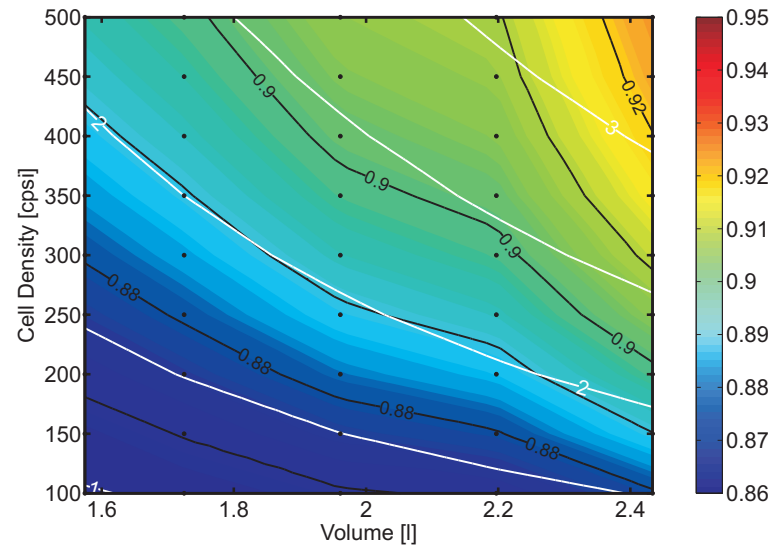

Figure 12: DPF filtration efficiency as a function of monolith volume and cell density for baseline TIF and soot loading conditions. Volume reduction defined by length reduction. 

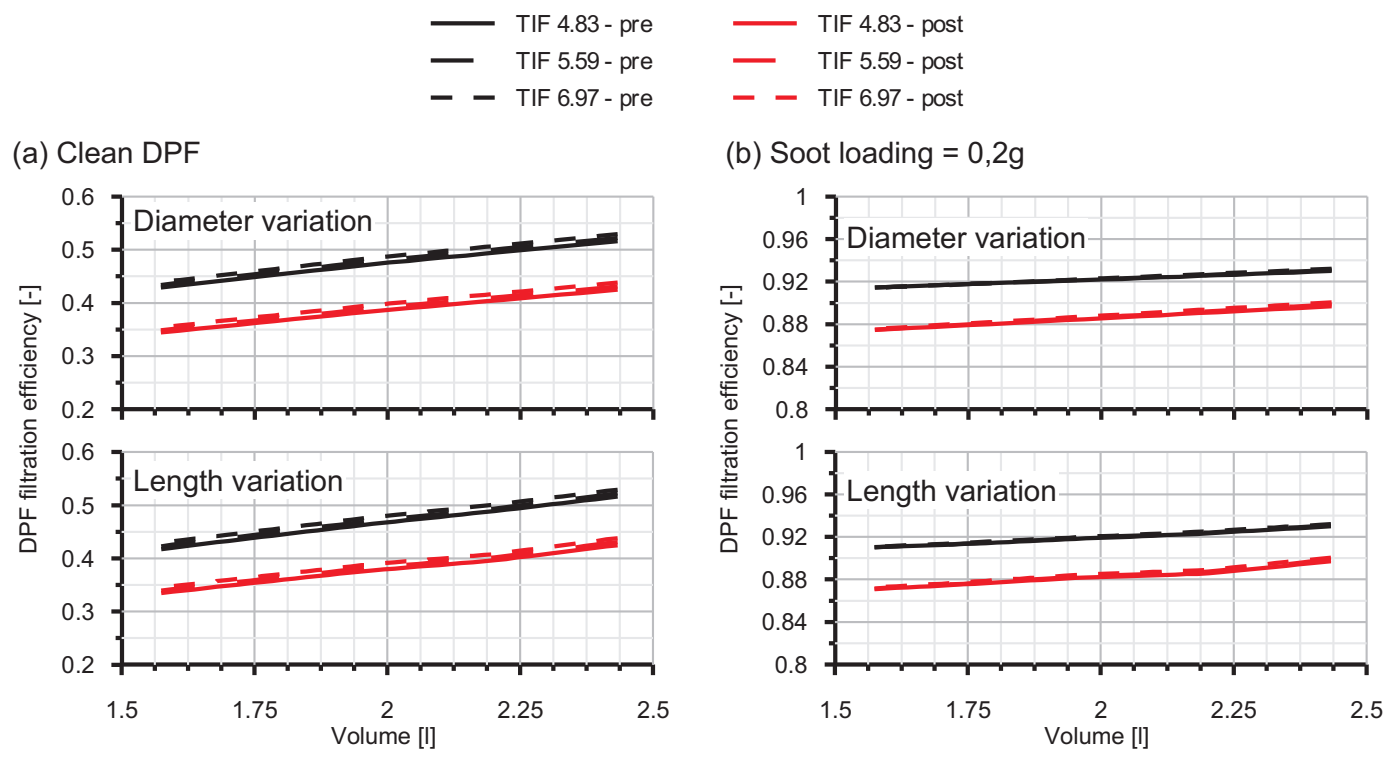

Figure 13: Effect of volume, TIF, placement and soot loading on the DPF filtration efficiency with constant SFA.

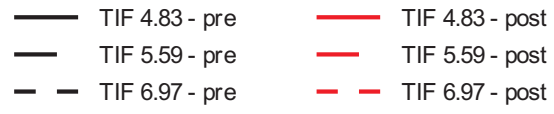

(a) Clean DPF

(b) Soot loading $=0,2 \mathrm{~g}$
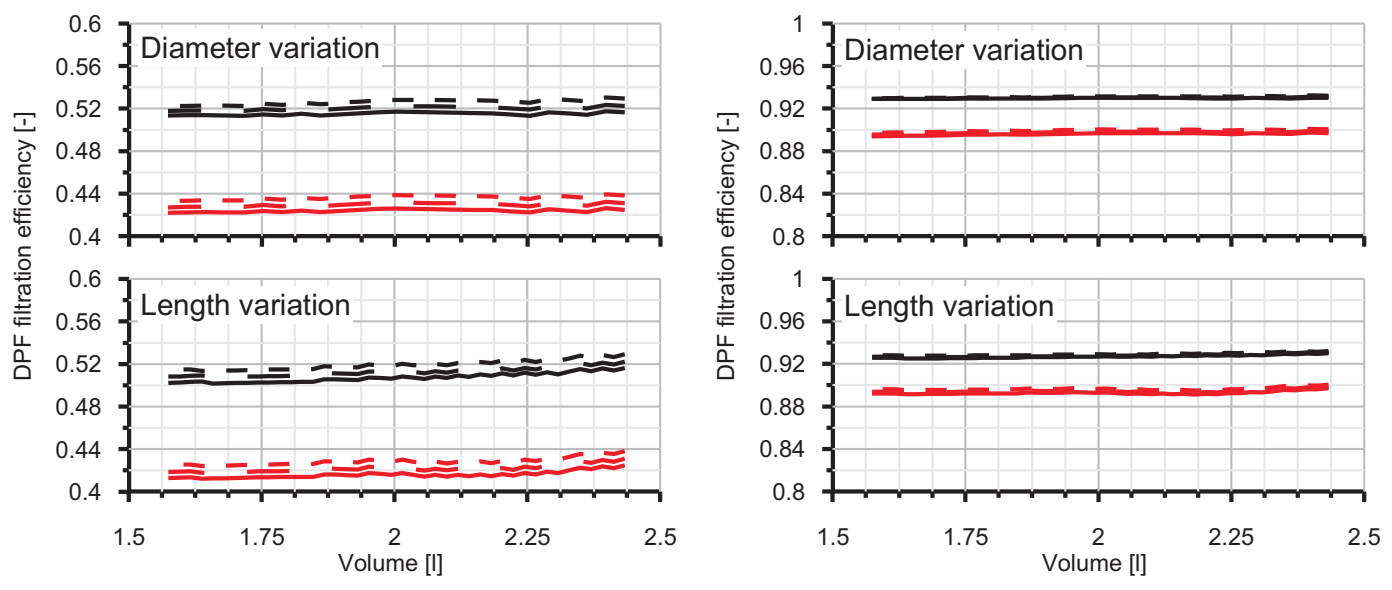

Figure 14: Effect of volume, TIF, placement and soot loading on the DPF filtration efficiency with constant filtration area. 